\title{
Heterogeneity, plot shape effect and optimum plot size
}

\author{
R. Zhang ${ }^{\mathrm{a}, 1}$, A.W. Warrick ${ }^{\mathrm{b}}$ and D.E. Myers ${ }^{\mathrm{c}}$ \\ aU.S. Salinity Laboratory, USDA, ARS, Riverside, CA, USA \\ ${ }^{\mathrm{b}}$ Department of Soil and Water Science, University of Arizona, Tucson, AZ, USA \\ 'Department of Mathematics, University of Arizona, Tucson, AZ, USA
}

(Received July 30, 1992; accepted after revision June 8, 1993)

\begin{abstract}
By introducing heterogeneity indices, an empirical equation is proposed for characterizing the heterogeneity of non-isotropic fields. The formula is an extension of Fairfield Smith's (1938) empirical law describing heterogeneity in isotropic fields. Based on these indices, criteria are provided for choosing optimum plot shapes in terms of minimizing the sample variance and cost. Sample plots having their largest dimension in the direction with the largest index will give more accurate results (less variable) than plots with other shapes. Relations between the optimum plot size and relative cost versus variogram parameters are given for several variogram models. These relations indicate that variograms with small effective ranges have a very profound effect on the optimum plot sizes.
\end{abstract}

\section{INTRODUCTION}

In the past several decades it has been clearly established that agricultural experiments carried out under field conditions are subject to an appreciable error, chiefly because of soil heterogeneity. In order to secure greater uniformity in soil conditions, the sample size and the shape of plots should be considered during the design and the sampling stages.

Many workers have studied the effect of plot shapes in controlling heterogeneity with various crops. However, the conclusions are contradictory. Working on their Mangold experiments, Mercer and Hall (1911) concluded that little could be deduced as to any superiority of long and narrow plots over square ones. On the other hand, Day (1920) pointed out that more accurate results were obtained from single plots which were long and narrow and which extended in the direction of greatest variation, than from those of other shapes. Kiesselbach (1923) demonstrated that the variability associated with oblong plots was smaller than with square ones. In a detailed study, Christidis (1931) concluded that the shape of the plots constituted an important means for controlling soil heterogeneity and that in no case could square plots be more uni-

\footnotetext{
${ }^{1}$ Present address: Department of Plant, Soil and Insects, University of Wyoming, P.O. Box 3354, Laramie, WY 82071-3354, USA.
} 
form than long and narrow ones. More extensive studies of crop yields were carried out by various other researchers (e.g. Koch and Rigney, 1951; Whittle, 1956; Weber and Horner, 1957; Kuehl and Kittock, 1969). Meanwhile, sample volume problems were also related to soil properties. Ball and Williams (1968) considered the relationship between sample volumes and variance in the measurement of soil chemical properties. The bulk (larger) samples gave much smaller variability. Additional spatial variability was found at two scales, among samples at a particular location and between locations within the two sites. Anderson and Bouma (1973) investigated the effect of different core heights on measured $K_{\text {sat }}$ values. Larger pores tend to become discontinuous throughout taller cores, which would result in a considerable decrease in the hydraulic conductivity and produce more consistent $K_{\text {sat }}$ values. Hawley et al. (1982) showed that the minimum desirable sampling volume depended on the homogeneity of a sampling area. Hassan et al. (1983) investigated the relationship between the chloride distribution and sample volume with depth. They suggested that using a larger volume sampler should allow for more consistent results, and as large a sample as possible should be taken to insure that a representative element on volume (REV) is sampled. Studying soil fertility, Gomez and Gomez (1984) concluded that long and narrow plots should be used for areas with a distinct fertility gradient, with the length of the plot parallel to the gradient of the field.

An alternative approach to the quantification of heterogeneity is through geostatistics. Heterogeneity was related to variograms, and variance was evaluated as a function of sample support within a finite domain. Results along these lines are given by Starks (1986) and Zhang et al. (1990). Crop heterogeneity has also been studied using geostatistical techniques by Bhatti et al. (1991).

The objective of this study is to derive a general empirical equation for characterizing the heterogeneity of non-isotropic fields. This equation will be tested with various sets of experimental data. Then the effects of various plot shapes are discussed, and criteria are given for choosing optimum plot shapes in order to reduce sampling variability and cost. Finally, optimum plot size and the relative sample cost are related to variogram parameters, based on the relationship between the indices of heterogeneity and the geostatistical models.

\section{HETEROGENEITY}

Fairfield Smith (1938) presented an empirical law relating the variance of crop yields per unit area to plot size by:

$V_{n}=V_{1} / n^{b}$

where $V_{n}$ is the variance among plots with an area of $n$ units and $V_{1}$ is the 
variance among plots of unit size. The factor $b$ is an index of heterogeneity. If the plots are spatially uncorrelated, then $b$ will be 1 . It could approach a limiting value of zero if no heterogeneity exists. If $n$ corresponds to an area $W$ and the support size of the basic plot is $w$, eq. (1) is equivalent to:

$V_{W}=V_{w}(w / W)^{b}$

with $V_{W}$ and $V_{W}$ corresponding to the two variances.

To take anisotropy into account, a general variance relationship similar to eq. (1) may be written as follows:

$V_{n, s}=V_{1} /\left(n_{1}^{b_{1}} n_{2}^{b_{2}}\right)$

where $n_{1}, n_{2}$ are the numbers of basic plots taken along the $X, Y$ directions, respectively; $V_{1}$ is the variance of the basic plots, $V_{n, s}$ the variance of plots each of which has $n=n_{1} n_{2}$ basic plots. $b_{1}$ and $b_{2}$ are indices which characterize the medium heterogeneity in the $X, Y$ directions of a 2-D field, respectively.

For an isotropic medium, $b_{1}=b_{2}$, eq. (3) becomes:

$V_{n, s}=V_{1} /\left(n_{1} n_{2}\right)^{b_{1}}$

which is essentially the same form as eq. (1). For a completely uniform field, $b_{1}=b_{2}=0$; and for a field with no spatial correlation, $b_{1}=b_{2}=1$.

Equation (3) can be written in a logarithmic form:

$\log \left(V_{n, s} / V_{1}\right)=-b_{1} \log \left(n_{1}\right)-b_{2} \log \left(n_{2}\right)$

which will be used to compute the indices of heterogeneity, i.e., $b_{1}$ and $b_{2}$, from available data. $V_{1}$ is calculated from the basic units (the original data), while $V_{n, s}$ is estimated from reconstructed plots each of which consists of $n_{1} n_{2}$ basic units. During the reconstruction of the plots, if $n_{2}$ is fixed (e.g. $n_{2}=1$ ) and $n_{1}$ is varied, i.e. $n_{1}=1,2,3, \ldots, V_{n, s}$ is a function of $n_{1}$ only. Therefore, the second term on the right-hand side in eq. (5) is a constant, and we can compute $b_{1}$ from the $\log \left(V_{n, s} / V_{1}\right)$ vs. $\log \left(n_{1}\right)$ relationship. Similarly if $n_{1}$ is fixed and $n_{2}$ is varied, $b_{2}$ can be computed from the relationship of $\log \left(V_{n, s} / V_{1}\right)$ vs. $\log \left(n_{2}\right)$. If the same number of units are taken in the $X$ and $Y$ directions, or $n_{1}=n_{2}$, we have:

$\log \left(V_{n, s} / V_{1}\right)=-\left(b_{1}+b_{2}\right) \log \left(n_{1}\right)=-b_{s} \log \left(n_{1}\right)$

Then $b_{s}$ can be obtained from the linear regression of $\log \left(V_{n, s} / V_{1}\right)$ on $\log \left(n_{1}\right)$. If eq. (3) is a reasonable mathematical form to characterize heterogeneity, the sum of $b_{1}$ and $b_{2}$ computed from eq. (5) should be close to $b_{s}$ independently computed from eq. (6). These equations will be verified by leastsquares linear regressions using various data sets.

The basic characteristics of the data sets used for this analysis are summa- 
rized in Table 1, which gives the crop name, the authors and the year of publication, the total number of data points (plots) and a brief description of each data set.

One example of the analysis of heterogeneity uses Mercer and Hall's (1911) wheat data. There are 25 columns in the $X$ direction (west-east) and 20 rows

TABLE 1

Basic information of yield data sets

\begin{tabular}{|c|c|c|c|}
\hline Crop/Location & Authors & Number & Description \\
\hline $\begin{array}{l}\text { Wheat grain } \\
\text { (Rothamsted) }\end{array}$ & $\begin{array}{l}\text { Mercer and Hall } \\
\quad(1911)\end{array}$ & 500 & $\begin{array}{l}25 \text { columns } \times 20 \text { rows of } 3.3 \\
\times 3.3 \text { m plots }\end{array}$ \\
\hline $\begin{array}{l}\text { Wheat straw } \\
\text { (Rothamsted) }\end{array}$ & $\begin{array}{l}\text { Mercer and Hall } \\
\quad(1911)\end{array}$ & 500 & same as above \\
\hline $\begin{array}{l}\text { Wheat } \\
\text { (Rothamsted) }\end{array}$ & $\begin{array}{r}\text { Kalamkar } \\
(1932)\end{array}$ & 1280 & $\begin{array}{l}16 \text { columns } \times 80 \text { rows } \\
\text { of } 0.15 \times 0.5 \mathrm{~m} \text { plots }\end{array}$ \\
\hline $\begin{array}{l}\text { Wheat (No. of ears) } \\
\text { (Rothamsted) }\end{array}$ & $\begin{array}{r}\text { Kalamkar } \\
(1932)\end{array}$ & 1280 & the same as above \\
\hline $\begin{array}{l}\text { Wheat } \\
\text { (Aberdeen, Idaho) }\end{array}$ & $\begin{array}{l}\text { Wiebe } \\
\qquad(1935)\end{array}$ & 1500 & $\begin{array}{l}4.57 \mathrm{~m} \text { of each row, } 0.305 \mathrm{~m} \text { apart, } \\
\text { grouped in } 12 \text { series of } 125 \text { rows each }\end{array}$ \\
\hline $\begin{array}{l}\text { Grain } \\
\text { (Cambridge Univ. } \\
\text { Farm) }\end{array}$ & $\begin{array}{r}\text { Christidis } \\
(1931)\end{array}$ & 288 & $\begin{array}{l}12 \text { columns } \times 24 \text { rows } \\
\text { of } 0.203 \times 2.286 \mathrm{~m} \text { plots. }\end{array}$ \\
\hline Rice (IR8) & $\begin{array}{l}\text { Gomez and Gomez } \\
\text { (1984) }\end{array}$ & 648 & $\begin{array}{l}18 \text { columns } \times 36 \text { rows } \\
\text { of } 1 \times 1 \mathrm{~m} \text { plots }\end{array}$ \\
\hline $\begin{array}{l}\text { Mangold leaf } \\
\text { (Rothamsted) }\end{array}$ & $\begin{array}{l}\text { Mercer and Hall } \\
\quad(1911)\end{array}$ & 200 & $\begin{array}{r}10 \text { columns } \times 20 \text { rows } \\
\text { of } 4.5 \times 4.5 \mathrm{~m} \text { plots }\end{array}$ \\
\hline $\begin{array}{l}\text { Mangold root } \\
\quad(\text { Rothamsted })\end{array}$ & $\begin{array}{l}\text { Mercer and Hall } \\
\text { (1911) }\end{array}$ & 200 & the same as above \\
\hline $\begin{array}{l}\text { Bean (Red Kidney) } \\
\quad(1954, \mathrm{CA})\end{array}$ & $\begin{array}{l}\text { Smith } \\
\quad(1958)\end{array}$ & 216 & $\begin{array}{l}18 \text { columns } \times 12 \text { rows } \\
\text { of } 0.76 \times 4.57 \mathrm{~m} \text { plots }\end{array}$ \\
\hline $\begin{array}{l}\text { Bean (Stand. Pink) } \\
(1954, \mathrm{CA})\end{array}$ & $\begin{array}{l}\text { Smith } \\
\quad(1958)\end{array}$ & 216 & the same as above \\
\hline $\begin{array}{l}\text { Bean (Red Kidney) } \\
(1955, \mathrm{CA})\end{array}$ & $\begin{array}{l}\text { Smith } \\
\quad(1958)\end{array}$ & 240 & $\begin{array}{l}16 \text { columns } \times 15 \text { rows } \\
\text { of } 1.52 \times 9.14 \mathrm{~m} \text { plots }\end{array}$ \\
\hline $\begin{array}{l}\text { Bean (Stand. Pink) } \\
\quad(1955, \mathrm{CA})\end{array}$ & $\begin{array}{l}\text { Smith } \\
\text { (1958) }\end{array}$ & 240 & the same as above \\
\hline $\begin{array}{l}\text { Potato } \\
\quad \text { (Saskatchewan) }\end{array}$ & $\begin{array}{r}\text { Kalamkar } \\
(1932)\end{array}$ & 576 & $\begin{array}{l}6 \text { columns } \times 96 \text { rows } \\
\text { of } 6.7 \times 0.91 \mathrm{~m} \text { plots }\end{array}$ \\
\hline $\begin{array}{l}\text { Cotton } \\
\quad(\text { Phoenix })\end{array}$ & $\begin{array}{l}\text { Kuehl and Kittock } \\
\text { (1969) }\end{array}$ & 432 & $\begin{array}{l}36 \text { columns } \times 12 \text { rows } \\
\text { of } 1.5 \times 1 \mathrm{~m} \text { plots }\end{array}$ \\
\hline $\begin{array}{l}\text { Navel orange } \\
\quad(\text { Riverside, } \mathrm{CA})\end{array}$ & $\begin{array}{l}\text { Batchelor and Reed } \\
\text { (1918) }\end{array}$ & 1000 & $\begin{array}{l}20 \text { rows with } 50 \text { trees in a row, } \\
\text { planted in a } 6.71 \times 6.71 \mathrm{~m} \text { area }\end{array}$ \\
\hline $\begin{array}{l}\text { Navel orange } \\
\quad(\text { Naranjo, CA) }\end{array}$ & $\begin{array}{l}\text { Batchelor and Reed } \\
\text { (1918) }\end{array}$ & 495 & $\begin{array}{l}15 \text { rows with } 33 \text { trees in a row, } \\
\text { planted in a } 6.71 \times 6.71 \mathrm{~m} \text { area }\end{array}$ \\
\hline $\begin{array}{l}\text { Valencia orange } \\
\text { (Valla Park, CA) }\end{array}$ & $\begin{array}{l}\text { Batchelor and Reed } \\
\quad(1918)\end{array}$ & 240 & $\begin{array}{l}12 \text { rows with } 20 \text { trees in a row, } \\
\text { planted in a } 6.55 \times 6.55 \mathrm{~m} \text { area }\end{array}$ \\
\hline $\begin{array}{l}\text { Eureka Lemon } \\
\quad(\text { Upland, CA })\end{array}$ & $\begin{array}{l}\text { Batchelor and Reed } \\
\text { (1918) }\end{array}$ & 364 & $\begin{array}{l}14 \text { rows with } 26 \text { trees in a row, } \\
\text { planted in a } 7.32 \times 7.32 \text { m area }\end{array}$ \\
\hline
\end{tabular}




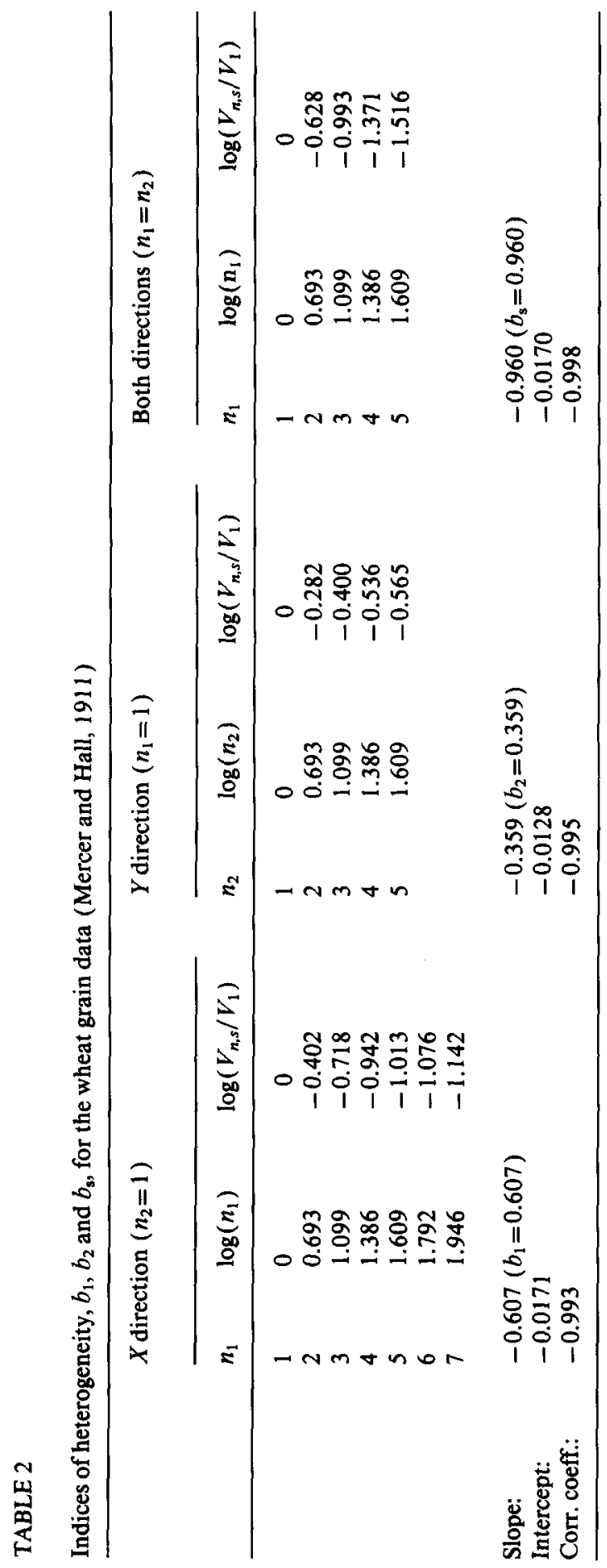


in the $Y$ direction (north-south). Different numbers of units along row and column directions are used to construct larger plots with different plot shapes. For instance, $n_{2} \times n_{1}=4 \times 3$ means that 4 units are taken along the $Y$ direction ( 4 rows) and 3 units along the $X$ direction ( 3 columns) to construct a new plot. The averaged value of the 12 units represents the value of the plot. We construct all new plots without overlapping. Then the variance is calculated by using the calculated mean for each specified plot shape. Table 2 shows the values of $b_{1}, b_{2}$ and $b_{s}$ calculated from the data. The index of heterogeneity $b_{1}$ along the $X$ direction is about twice that along the $Y$ direction, $b_{2}$, which indicates that the field is non-isotropic. The sum of $b_{1}(0.607)$ and $b_{2}(0.359)$ is close to $b_{s}(0.960)$. It should be pointed out that the $b$ value $(0.46)$ listed in Smith's paper (1938) is an averaged index of the field which is close to $b_{s} /$ $2=0.48$ of our analysis.

Table 3 summarizes the $b_{1}, b_{2}$ and $b_{s}$ values for the various data sets considered. These data might be considered as a sample in a meta-analysis to answer the question whether eq. (3) adequately corresponds to a decomposition of the exponent $b_{s}$ reflecting anisotropies when present. Using these values we can test whether the sum of $b_{1}$ and $b_{2}$ differs significantly from $b_{s}$, that is, whether $b_{1}+b_{2}-b_{s}$ differs significantly from zero. Utilizing the 19 triples, the

TABLE 3

Summation of values of $b_{1}$ and $b_{2}$ computed with eq. (5), and $b_{\mathrm{s}}$ computed with eq. (6) of different data sets

\begin{tabular}{lllll}
\hline Crops & Authors & $b_{1}$ & $b_{2}$ & $b_{s}$ \\
\hline Wheat grain & Mercer and Hall (1911) & 0.607 & 0.359 & 0.960 \\
Wheat straw & Mercer and Hall (1911) & 0.463 & 0.290 & 0.618 \\
Wheat & Kalamkar (1932a, b) & 0.558 & 0.835 & 1.418 \\
Wheat (\# of ears) & Kalamkar (1932a, b) & 0.585 & 0.781 & 1.288 \\
Wheat & Wiebe (1935) & 0.303 & 0.163 & 0.468 \\
Grain & Christidis (1931) & 0.794 & 0.265 & 1.110 \\
Rice (IR8) & Gomez and Gomez (1984) & 0.180 & 0.184 & 0.362 \\
Mangold leaf & Mercer and Hall (1911) & 0.858 & 0.273 & 1.340 \\
Mangold root & Mercer and Hall (1911) & 0.486 & 0.569 & 1.138 \\
Bean (Red Kidney) & Smith (1958) & 0.363 & 0.457 & 0.917 \\
Bean (Stand. Pink) & Smith (1958) & 0.635 & 0.497 & 0.954 \\
Bean (Red Kidney) & Smith (1958) & 0.403 & 0.467 & 0.917 \\
Bean (Stand. Pink) & Smith (1958) & 0.466 & 0.655 & 0.994 \\
Potato & Kalamkar (1932a, b) & 0.269 & 0.142 & 0.359 \\
Cotton & Kuehl and Kittock (1969) & 0.605 & 0.536 & 0.965 \\
Navel orange & Batchelor and Reed (1918) & 0.325 & 0.418 & 0.629 \\
Navel orange & Batchelor and Reed (1918) & 0.546 & 0.368 & 0.693 \\
Valencia orange & Batchelor and Reed (1918) & 0.470 & 0.678 & 1.082 \\
Eureka Lemon & Batchelor and Reed (1918) & 0.538 & 0.341 & 0.780 \\
\hline
\end{tabular}


sum-difference is computed and then tested using a $t$-statistic with 18 degrees of freedom. The computed $t$-value is 1.313 compared with the tabled value of 1.734 at the 0.05 level, hence the null hypothesis of a zero sum-difference would be accepted.

Alternatively $b_{1}+b_{2}$ can be graphically compared with $b_{s}$ as shown in Fig. 1. The regression line of $b_{s}$ on $b_{1}+b_{2}$ has a slope of 0.971 and the $r^{2}$ value is 0.854 . These results indicate that eq. (3) is an appropriate tool to characterize non-isotropic features of soils.

\section{EFFECT OF PLOT SHAPES}

Since the regression of variance on plot size is a function of the correlation of adjacent areas, plot shape has an effect on the regression as reflected by eq. (3). Based on the indices of heterogeneity, the shape effect, i.e., the change in the variance with different plot shapes, is shown in the following examples. Again Mercer and Hall's (1911) wheat data are used. We change plot size from one basic unit to four units in 3 ways: (A) four basic units along the $X$ direction, i.e., 1 row and 4 columns in each larger plot; (B) four units along the $Y$ direction, i.e., 4 rows and 1 column; (C) square plots with 2 rows and 2 columns. For shape A the variance changes from 0.210 for the basic units to:

$V_{1} /\left(n_{1}^{b_{1}} n_{2}^{b_{2}}\right)=0.210 /\left(4^{0.607} 1^{0.359}\right)=0.0904$

for the larger plots. For shape $B$, the variance is:

$V_{1}\left(n_{1}^{b_{1}} n_{2}^{b_{2}}\right)=0.210 /\left(1^{0.607} 4^{0.359}\right)=0.125$

The variance for the square plots is given by:

$V_{1}\left(n_{1}^{b_{1}} n_{2}^{b_{2}}\right)=0.210 /\left(2^{0.607} 2^{0.359}\right)=0.107$

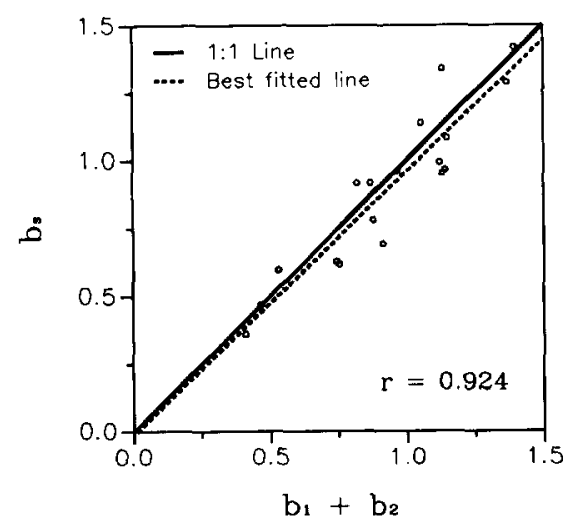

Fig. 1. Comparison between sum of $b_{1}$ and $b_{2}$ computed with eq. (5) and $b_{s}$ computed with eq. (6). 

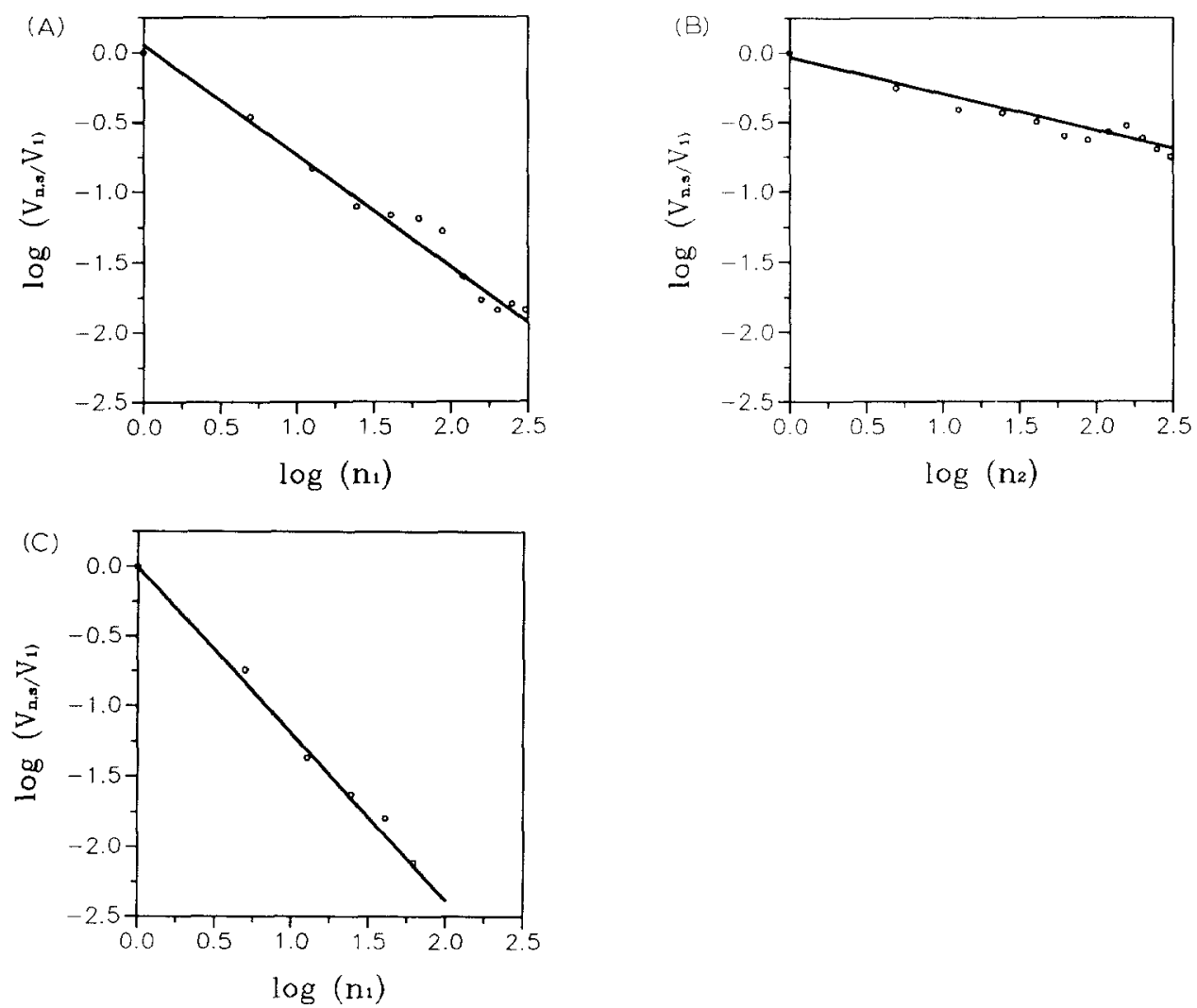

Fig. 2. Linear regressions of (A) $\log \left(V_{n, s} / V_{1}\right)$ vs. $\log \left(n_{1}\right)\left(n_{2}=1\right)$, (B) $\log \left(V_{n, s} / V_{1}\right)$ vs. $\log \left(n_{2}\right)$ $\left(n_{1}=1\right)$, (C) $\log \left(V_{n, s} / V_{1}\right)$ vs. $\log \left(n_{1}\right)\left(n_{1}=n_{2}\right)$.

or:

$V_{1} / n_{1}^{b_{s}}=0.210 / 2^{0.96}=0.108$

In terms of variance reduction, plot shape $A$ is $38 \%$ more efficient than $B$ and $19 \%$ than $C$, and $C$ is $17 \%$ more efficient than $B$.

The second example shows soil heterogeneity based on the wheat yield data reported by Christidis (1931). From the regression line slopes for $\log \left(V_{n, s} /\right.$ $\left.V_{1}\right)$ vs. $\log \left(n_{1}\right)$ or $\log \left(V_{n, s} / V_{1}\right)$ vs. $\log \left(n_{2}\right)$ in Fig. $2 \mathrm{~A}, \mathrm{~B}$, and C, we obtain the indices of heterogeneity, $b_{1}, b_{2}$ and $b_{s}$, as $0.794,0.265$ and 1.110 , respectively. Table 4 presents the relationships between the variances, coefficients of variation (CV), the units, and ratio of width and length $(W / L)$ of the reconstructed plots. This table illustrates that plots with the same area have different coefficients of variation or variance for different shapes. For instance, for plots with 9 units, the variance for plots with $n_{1}=1, n_{2}=9$ (W/ 


\section{TABLE 4}

The relationships between the variance, coefficient of variation (CV), basic units and the ratio of width and length $(W / L)$ in reconstructed plots for the yield data (Christidis, 1931)

\begin{tabular}{|c|c|c|c|}
\hline Units & $W / L$ & CV $(\%)$ & Var. $\left(g^{2}\right)$ \\
\hline 1 & $1 / 11.25$ & 19.81 & 192 \\
\hline \multirow[t]{2}{*}{2} & $1 / 22.5$ & 15.73 & 121 \\
\hline & $1 / 5.63$ & 17.46 & 149 \\
\hline \multirow[t]{2}{*}{3} & $1 / 33.75$ & 13.07 & 84 \\
\hline & $1 / 3.75$ & 16.12 & 127 \\
\hline \multirow[t]{3}{*}{4} & $1 / 45$ & 11.39 & 64 \\
\hline & $1 / 11.25$ & 13.67 & 92 \\
\hline & $1 / 2.81$ & 15.95 & 125 \\
\hline \multirow[t]{2}{*}{5} & $1 / 56.25$ & 11.06 & 60 \\
\hline & $1 / 2.25$ & 15.42 & 117 \\
\hline \multirow[t]{4}{*}{6} & $1 / 67.5$ & 10.93 & 58 \\
\hline & $1 / 16.85$ & 11.18 & 61 \\
\hline & $1 / 7.5$ & 12.48 & 76 \\
\hline & $1 / 1.88$ & 14.65 & 105 \\
\hline \multirow[t]{2}{*}{7} & $1 / 78.75$ & 7.74 & 29 \\
\hline & $1 / 1.61$ & 14.46 & 102 \\
\hline \multirow[t]{4}{*}{8} & $1 / 90$ & 8.89 & 39 \\
\hline & $1 / 22.5$ & 9.18 & 41 \\
\hline & $1 / 5.63$ & 12.51 & 77 \\
\hline & $1 / 1.41$ & 14.87 & 108 \\
\hline \multirow[t]{3}{*}{9} & $1 / 101.3$ & 8.17 & 33 \\
\hline & $1 / 11.25$ & 10.00 & 49 \\
\hline & $1 / 1.25$ & 15.20 & 113 \\
\hline \multirow[t]{4}{*}{10} & $1 / 112.5$ & 7.89 & 30 \\
\hline & $1 / 28.13$ & 9.17 & 41 \\
\hline & $1 / 4.5$ & 11.64 & 66 \\
\hline & $1 / 1.13$ & 14.56 & 104 \\
\hline \multirow[t]{2}{*}{11} & $1 / 123.8$ & 8.06 & 32 \\
\hline & $1 / 1.023$ & 13.95 & 95 \\
\hline \multirow[t]{4}{*}{12} & $1 / 135$ & 7.87 & 30 \\
\hline & $1 / 33.75$ & 9.22 & 42 \\
\hline & $1 / 3.75$ & 11.37 & 63 \\
\hline & $1 / 0.94$ & 13.59 & 90 \\
\hline
\end{tabular}

$L=1 / 1.25)$ is about 4 times as that for plots with $n_{1}=9$ and $n_{2}=1(W / L=$ 1/101.3). These results support Christidis' (1931) conclusion, that is, for plots with the same area, the smaller the value of $W / L$ the more uniform the experimental plots. Note that "uniform" used here does not mean that the plots are internally homogeneous, but that the variance between them is small. In this case, because the dimension of the units along the $X$ direction (the length) is more than 11 times larger than that along the $Y$ direction (the width) and $b_{1}$ is about 3 times as large as $b_{2}$, plots close to square ( $W / L$ close to 1$)$ have larger variance than long plots.

An index RV for relative differences of variances is defined by: 


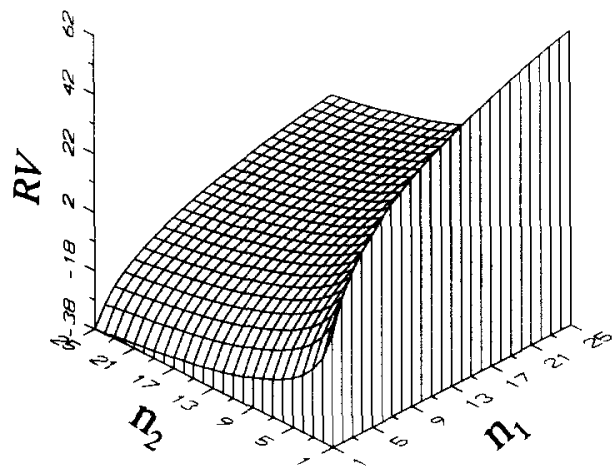

Fig. 3. Relative difference of variances, RV, as a function of plot units and shapes, i.e., the numbers of units along $X$ and $Y, n_{1}$ and $n_{2}$.

$\mathrm{RV}=100\left(V_{n, s}-V_{n}\right) / V_{n}$

where $V_{n, s}$ is computed using eq. ( 3 ) and:

$V_{n}=V_{1} /\left(n_{1} n_{2}\right)^{0.5\left(b_{1}+b_{2}\right)}$

which represents the variance assuming that the field is isotropic. The effect of plot shapes on the variance is shown in Fig. 3 taking the heterogeneity indices along $X$ and $Y$ as $b_{1}=0.3$ and $b_{2}=0.6$, respectively. If the plot dimension is increased along $Y$, the relative difference of variances is negative and its absolute value increases. That is, the efficiency of reducing variance increases as the dimension of plot in the $Y$ direction or $n_{2}$ increases because the heterogeneity index along $Y$ is larger than that along $X$. On the other hand, $\mathrm{RV}$ increases, i.e., the efficiency decreases as the units along $X\left(n_{1}\right)$ increase.

As illustrated by the above examples, plot shapes affect sample variance. In a non-isotropic field, the relationship between sample variance and plot shapes is determined by the heterogeneity indices. Sample plots having their greatest dimension in the direction with the greatest index will give more accurate results (less variation) than plots with other shapes.

\section{OPTIMUM PLOT SIZE}

From the previous discussion it is clear that variability decreases as plot size increases. Nevertheless, the rate of decrease in variability becomes less as the plot size increases. Meanwhile higher sampling costs are involved when larger plots are used. Therefore, the plot size that a researcher should aim for is one which balances precision and cost. This is commonly referred to as the optimum plot size.

If the cost per plot is given by a linear relation (Smith, 1938; Weber and Horner, 1957): 
$K_{1}+K_{2} n$

an objective function accounting for both cost and variance in an isotropic field can be expressed by:

$C=\left(K_{1}+K_{2} n\right) V_{1} / n^{b}$

where $n_{0}$ is the number of the units in a chosen plot, $K_{1}$ is the cost proportional to the number of plots per treatment, and $K_{2}$ is the cost proportional to the area per treatment. The objective function is minimized when:

$n_{0}=K_{1} b /\left[K_{2}(1-b)\right]$

where $n_{0}$ is the optimum plot size in terms of number of basic units. Let $K=K_{1} / K_{2}$, we have:

$n_{0} K=b /(1-b)$

The objective function can be rewritten as:

$C=K_{1}\left[1+\frac{b}{1-b} z\right] V_{1} / n^{b}$

where $z$ is the ratio of the plot size used with $n$ units to the most efficient size with $n_{0}$ units, i.e., $n / n_{0}$. Using Smith's (1938) definition, the relative cost is:

$y=C / C_{\min }=b z^{(1-b)}+(1-b) z^{-b}$

where $C$ is the cost related to variance for a specified plot size, $C_{\min }$ is the cost related to variance for the optimum plot size.

Zhang et al. (1990) have studied variance as a function of sample support size using geostatistics. They related the index of heterogeneity, $b$, to the area of basic units $(w)$ and the range of a variogram $(a)$. The common variograms used include exponential, spherical, Gaussian and Michaelis-Menton models (e.g., table 1 in Zhang et al., 1990). The range of a variogram is a characteristic length and can be used to define an effective range. The effective range is defined as a distance where a variogram reaches 95 percentage of its sill value. By eq. (16) and the relationships between $b$ and $w / a^{2}$ (Zhang et al., 1990 ), we can relate $n_{0} / K$ to $w / a^{2}$. The relationship presented in Fig. 4 shows that $n_{0} / K$ increases as $w / a^{2}$ increases. This means that the optimum plot size is larger in a relatively random field (i.e., with a small range) than in a spatially correlated field. The relationships between $\log \left(w / a^{2}\right)$ vs. $\log \left(n_{0} / K\right)$ for spherical, exponential and Gaussian models are approximately linear. For the Michaelis-Menton model, as $w / a^{2}$ increases to infinite, $n_{0} / K$ seems to approach 1 . For variograms with shorter effective ranges, such as a spherical model, $n_{0} / K$ changes faster vs. $w / a^{2}$ than one with larger effective range, such as a Michaelis-Menton model. 


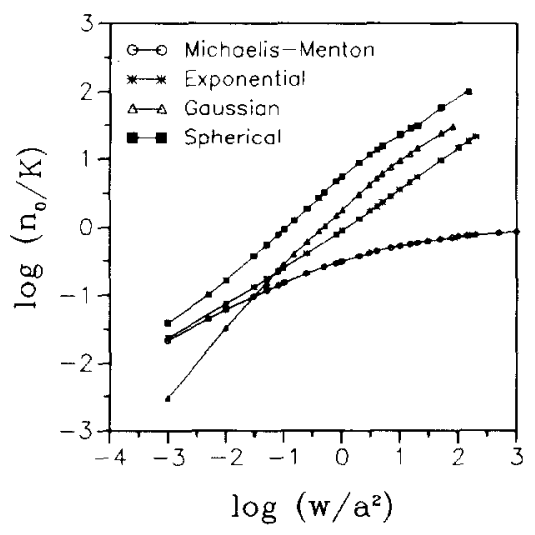

Fig. 4. Relationship between optimum plot size and $w / a^{2}$ for spherical, exponential, Gaussian and Michaelis-Menton models, where $w$ is the area of basic units and $a$ is the range of a variogram.

Combining the relationships between $b$ and $w / a^{2}$ and eq. (18), the relationships between $w / a^{2}$ vs. relative cost for spherical, exponential, Gaussian and Michaelis-Menton models are shown in Figs. 5A, B, C and D, respectively. For each specified $z$, there is a peak in each of the curves, which is determined by setting the first derivative of $y$ with respect to $b$ to zero resulting in:

$b=1 / \log (z)-1 /(z-1)$

The positions of the peaks are related to the effective ranges of the variograms. The peak goes to the far right for a variogram with a large effective range. The peak of the curves is the maximum relative cost. For a specified $z$, the maximum relative cost is the same for the different models; however, the shapes of the relative cost curves are different. The curves spread out for variograms with large effective ranges. In other words, $w / a^{2}$ affects relative cost in a relatively short range for a model with short effective range. If a value of $z$ is farther away from 1 , the relative cost is higher, or the efficiency decreases more. The effect of $z$ on efficiency may extend to a larger range of $w / a^{2}$ for a variogram with larger effective range. The curves of $\log \left(w / a^{2}\right)$ vs. relative cost for $z_{1}$ and $z_{2}$ have the same maximum value if $z_{2}=1 / z_{1}$. This is because from eq. (19):

$b^{*}=\frac{1}{\log \left(z_{2}\right)}-\frac{1}{\left(z_{2}-1\right)}=\frac{z_{1} \log \left(z_{1}\right)-\left(z_{1}-1\right)}{\left(z_{1}-1\right) \log \left(z_{1}\right)}=1-b$

resulting in:

$y_{\max }^{*}=b^{*} z_{2}^{\left(1-b^{*}\right)}+\left(1-b^{*}\right) z_{2}^{-b^{*}}=(1-b) z_{1}^{-b}+b z_{1}^{(1-b)}=y_{\max }$

However, the position of the maximum for $z_{2}$ is shifted compared to that for $z_{1}$. Figure 5C shows one example with $z_{1}=20$ and $z_{2}=1 / 20$. 

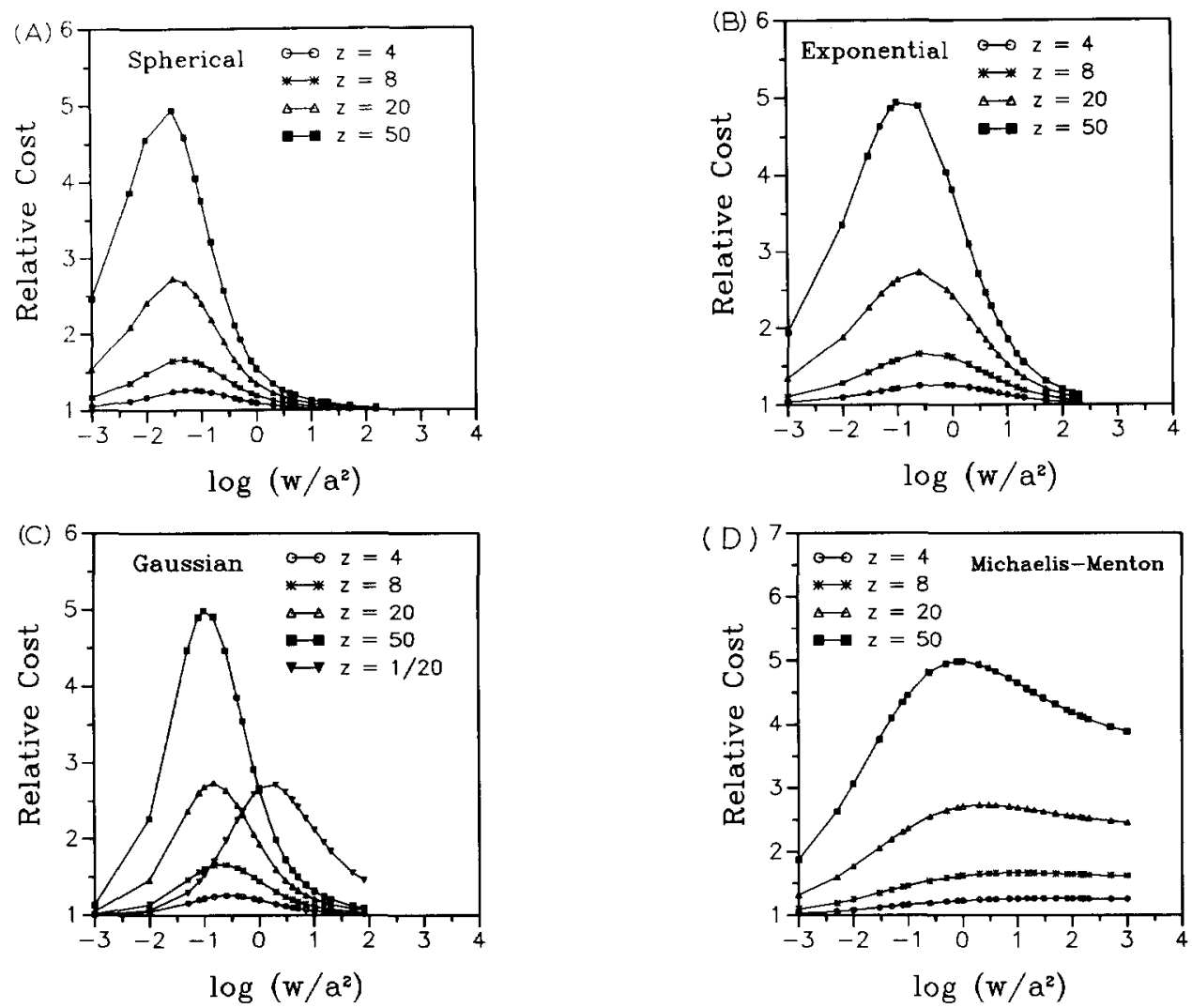

Fig. 5. Relationships between the relative cost and $w / a^{2}$ for (A) spherical, (B) exponential, (C) Gaussian and (D) Michaelis-Menton models, where $w$ is the area of basic units and $a$ is the range of a variogram. The parameter $z$ is the ratio of the plot size used with $N$ units to the most efficient size with $n_{0}$ units, i.e., $n / n_{0}$.

In non-isotropic fields, the cost per plot may be given by:

$K_{1}+K_{2} n_{1} n_{2}$

then the objective function accounting for both cost and variance is:

$$
\left(K_{1}+K_{2} n_{1} n_{2}\right) V_{1} / n_{1}^{b_{1}} n_{2}^{b_{2}}
$$

where $n_{1} n_{2}$ is the number of basic units in a chosen plot. When $b_{1} \leqslant 0.5$ and $b_{2} \leqslant 0.5$, eq. (23) is a monotone increasing function of $n_{1}$ and $n_{2}$. When $b_{1}$ or/and $b_{2}$ are greater than 0.5 , the minimum value of eq. (23) depends on the larger value of the heterogeneity indices. If $b_{1}>b_{2}$, eq. (23) has a minimum value when:

$n_{1}=K_{1} b_{1} /\left[K_{2}\left(1-b_{1}\right)\right]$ 
and $n_{2}=1$. On the other hand, eq. (23) has a minimum value when:

$n_{2}=K_{1} b_{2} /\left[K_{2}\left(1-b_{2}\right)\right]$

and $n_{1}=1$. Using Christidis' (1931) wheat data as an example, we have:

$n_{1}=0.794 K_{1} /\left[K_{2}(1-0.794)\right]=3.85 K_{1} / K_{2}$

and $n_{2}=1$ for the optimum plot size.

\section{CONCLUSIONS}

In general, real fields are anisotropic, so the effects of plot shapes should be taken into account in the sampling strategy. The plot shape that minimizes the sampling variance and cost depends on the indices of heterogeneity, i.e., $b_{1}$ and $b_{2}$ in the $X$ and $Y$ directions, respectively. If $b_{1}>b_{2}$, plots having their greatest dimensions in the $X$ direction will give more accurate results (less variable) than plots with other shapes. Plots having the same number of units in either direction will give more accurate results than plots having their greatest dimensions in the $Y$ direction. If $b_{2}>b_{1}$, plots having their greatest dimensions in the $Y$ direction will be more uniform than square plots. Square plots will be more uniform than plots having their greatest dimension in the $X$ direction. If $b_{1}=b_{2}$, the field is isotropic and squares are more uniform than other shapes. This kind of shape effect is discussed in detail by Zhang et al. (1990) and is not considered in the anisotropic fields. If an investigator cannot ascertain in which direction the field is most variable, he would probably use square plots.

Optimum plot sizes are related to heterogeneity indices and variograms. A variogram with a smaller effective range has more profound effect on the optimum plot size. Compared with the optimum plot size, the relative cost of different plot sizes is shown to be a function of the ratio of a basic plot area and a variogram range. For a non-isotropic field, the optimum plot size depends on the largest heterogeneity index in the $X$ or $Y$ directions, that is, it depends on the direction of the greatest heterogeneity in properties of the field. By considering the spatial variability of heterogeneous soils these relations may provide guidelines for sampling efficiency in terms of cost and precision.

\section{REFERENCES}

Anderson, J.L. and Bouma, J., 1973. Relationships between saturated hydraulic conductivity and morphometric data of an argilic horizon. Soil Sci. Soc. Am. J., 37: 408-412.

Ball, D.F. and Williams, W.M., 1968. Variability of soil chemical properties in two uncultivated brown earths. J. Soil Sci., 19: 379-391. 
Batchelor, H.E. and Reed, A.T., 1918. Relation of the variability of yields of fruit trees to the accuracy of field trials. J. Agric. Res., 12: 245-283.

Bhatti, A.U., Mulla, D.J., Koehler, F.E. and Gurmani, A.H., 1991. Identifying and removing spatial correlation from yield experiments. Soil Sci. Am. J., 55: 1523-1528.

Christidis, B.G., 1931. The importance of the shape of plots in field experimentation. J. Agric. Sci., 21: 14-37.

Day, J.W., 1920. The relation of size, shape and number of replications of plots to probable error in field experimentation. Agron. J., 12: 100-105.

Gomez, K.A. and Gomez, A.A., 1984. Statistical Procedures for Agricultural Research. 2nd ed. Wiley-Interscience, New York.

Hassan, H.M., Warrick, A.W. and Amoozegar-Fard, A., 1983. Sampling volume effects on determining salt in a soil profile. Soil Sci. Am. J., 47: 1265-1267.

Hawley, M.E., Richard, H.M. and Thomas, J.J., 1982. Volume-accuracy relationship in soil moisture sampling. J. Irrig. Drain. ASCE, 108: 1-11.

Kalamkar, R.J., 1932a. Experimental error and the field-plot technique with potatoes. J. Agric. Sci., 22: 373-385.

Kalamkar, R.J., 1932b. A study in sampling technique with wheat. J. Agric. Sci., 22: 783-796.

Kiesselbach, T.A., 1923. Competition as a source of error in comparative corn yield. Agron. J., 15: 199-215.

Koch, E.J. and Rigney, J.A., 1951. A method of estimating optimum plot size from experimental data. Agron. J., 43: 17-21.

Kuehl, R.O. and Kittock, D.L., 1969. Estimate of optimum plot size for cotton yield trials. Agron. J., 61: 584-586.

Mercer, W.B. and Hall, A.D., 1911. The experimental error of field trials. J. Agric. Sci., 4: 107132.

Smith, F.L., 1958. Effects of plot size, plot shape, and number of replications on the efficiency of bean yield trials. Hilgardia, 28: 43-63.

Smith, H.F., 1938. An empirical law describing heterogeneity in the yields of agricultural crops. J. Agric. Sci., 28: 1-23.

Starks, T.H., 1986. Determination of support in soil sampling. Math. Geol., 18: 529-538.

Weber, C.R. and Horner, T.W., 1957. Estimates of cost and optimum plot size and shape for measuring yield and chemical characters in soybeans. Agron. J., 49: 444-449.

Whittle, P., 1956. On the variation of yield variance with plot size. Biometrika, 43: 337-343.

Wiebe, G.A., 1935. Variation and correlation in grain yield among 1500 wheat nursery plots. J. Agric. Res., 50: 331-357.

Zhang, R., Warrick, A.W. and Myers, D.E., 1990. Variance as a function of sample support size. Math. Geol., 22: 107-121. 